\title{
Impact of Perceived Behavioral Control on E-learning Adoption
}

\author{
D. A. Gayan Nayanajith \& K. A. Damunupola \\ dagnsrilanka@gmail.com \\ Faculty of Graduate Studies \\ University of Kelaniya, Sri Lanka
}

\begin{abstract}
E-learning adoption (AEL) is a contextual phenomenon. Therefore, this research attempted to identify the association of adoption constructs and perceived behavioral control (PBC) on AEL in Sri Lankan private international schools' context. The sample consisted of students of three leading international school chains. Respondents were selected on multi-level cluster sampling method as per provinces/districts and major cities in which these schools are in operation. Overall, 450 questionnaires were distributed and 271 completed and returned questionnaires (60\%) were considered for the final data analysis. $A$ deductive methodology and quantitative method had been followed in the research. PBC factors were identified by conducting PCA. TAM, extended by using the PBC. The empirical evidence supported the positive relationship of adoption variable and $P B C$ variable towards AEL by correlation analysis and hierarchical regression analysis. The presence of differences in AEL between the students engaged in aesthetic subjects and science subject categories were also supported by the contrast test of ANOVA. ANCOVA revealed that the covariate; age was not significantly related to the student's AEL while the Hayes's process for moderation analysis has confirmed the relationship between $P B C$ and AEL is being moderated by student's age.
\end{abstract}

Key Words: Behavioral control, Demographic variables, E-learning, international schools, Sri Lanka

\section{Introduction}

Technology entwined fast-paced life styles necessitated educators all over the world to utilize technology to assist in providing the best learning experience for children which initially began as the computer aided learning that now encompasses tabs, cloud-based systems with industry 4.0 developments. Traditionally, the use of Information and Communications Technology (ICT) in education sector has been segregated from the traditional teaching environment: personal computers were designated to a separate computer lab where students were required to visit and perform only what is related to IT based-topics. Recently, smaller devices such as laptops, tablets and different kinds of mobile devices are being used regularly within classrooms as tools to assist students to supplement their daily lessons. 
Continued dedication was demonstrated by Sri Lankan authorities with policy making and reforms on education with a view to achieve dynamic comparative advantage for the economy. This is witnessed by developing a medium-term strategic plan for the period of 2018 to 2025, while formulating a national policy for science, technology, engineering and mathematics education, aligning to policy agenda of the government. Moreover, there is continuous improved involvement by the non-state institutions in education services as indicated by the number of private schools, international schools and 'pirivenas' which stood at correspondingly 106, 294 and 759 number of such institutions (CBSL, 2019). With the expansion of technology-based education facilities, initiatives have been taken to commence a pilot project on digital classrooms, in tandem with internet mediated education whilst formulating the ICT education master plan (CBSL, 2019). Although the literacy rate is high is Sri Lanka, there is a huge potential for development in electronically mediated education, particularly in e-learning sphere while addressing anytime anywhere access for teaching/learning process for both the students and teachers alike with a view to optimize investments in education, in the long run.

This study attempts to identify and comprehend what is the relationship of perceived behavioral control, perceived usefulness, perceived ease of use, subject categories towards students' adoption of e-learning in the context of leading private international school chains in Sri Lanka. Perceived behavioural control is an additional construct suggested to cater for explaining nonvolitional actions. It is defined as "people's perception of the ease or difficulty of performing the behaviour of interest (Ajzen, 1991, p. 183). PU is the one's perception of degree of enhancement of a particular task by a system and PEOU is the effort freeness of a system (Davis, 1989). To elaborate simply, perceived behavioural control that refers to the degree to which a person believes that they control any given behaviour. The theory of planned behaviour suggested that the people are much more likely to intend to enact certain behaviours when they feel that they can enact them successfully. Increased perceived behavioural control is a mix of two dimensions namely, self-efficacy and controllability. Self-efficacy refers to the level of difficulty that is required to perform the behaviour, or one's belief in their own ability to succeed in performing the behaviour (Ajzen, 2002; Ajzen, 1991). Controllability refers to the outside factors and one's belief that they personally have control over the performance of the behaviour, or if it is controlled by externally, uncontrollable factors. If a person has high perceived behavioural control, then they have an increased confidence that they are capable of performing the specific behaviour successfully which in this study refers to as adoption of e-learning, to be specific.

Furthermore, perceived ease of use is a predictor of perceived usefulness; both the perceived usefulness and the attitude of the user are being predictors of intention to use e-learning services (Liu, Liao \& Pratt, 2009). Variables pertinent to technology adoption model, are significantly predicting the acceptance of e-learning (Masrom, 2007). Determinants of the technology acceptance model are the major factors influencing the adoption of the technology related to e-learning (Cheung \& Vogel, 2013). Similarly, the association of different subject areas such as science, mathematics, engineering, technology and technology acceptance in accordance with psychological traits and learner beliefs have been highlighted by several researchers in different frameworks as well (Al-Azawei, Parslow\& Lundqvist, 2017; Jalali et al., 2018). Since the country specific dynamics and specific user related perspective are important, present study is postulated 
to identify the association of perceived behavioral control, perceived usefulness, perceived ease of use, subject categories towards students' adoption of e-learning in the context of leading Sri Lankan private international school chains that are operating in the country at present.

Significance of the research is that the contribution to both the theory and practice perspectives on adoption of e-learning, particularly in the developing country's perspective by incorporating interrelated models on technology adoption.

\section{Objectives}

Primary objective of the research was to identify the effect of perceived behavioral control (PBC) on students' adoption of e-learning (AEL) in the context of leading private international school chains in Sri Lanka. Secondly, identify the effect of TAM predictors namely perceived usefulness (PU) and perceived ease of use (PEOU), on AEL is also investigated. Thirdly, research attempted to identify whether there are any differences in adoption, based on different subject categories. Demographic variable age has been used by way of student's school grade to inquire into whether there is a moderation effect of age in between the relationship of PBC and AEL. Simultaneously impact of the covariate; age on AEL also been investigated during the study.

\section{Conceptual Framework and Hypotheses of The Study}

TAM is an extended explanation of Ajzen and Fishbein's theory of reasoned action (TRA). Davis's TAM (Davis, 1989; Davis, Bagozzi, \&Warshaw, 1989) is applied extensively to understand user adoption and usage of technology in different contexts as well (Venkatesh, 2000; Nayanajith et al., 2019a; Nayanajith et al., 2020a). TAM was developed by Fred Davis and Richard Bagozzi (Davis 1989; Bagozzi, Davis \&Warshaw 1992).TAM is an adaptation of TRA for information systems field. TAM has been used widely across different fields of study such as healthcare services, online banking services, hospitality services and etc. to understand innovative technology adoption in respective fields. Numerous attempts to extend TAM (e.g., TAM2) have generally guided largely by one of the following 3 approaches: by incorporating factors from interconnected models on customer adoption, by means of integrating additional or alternative belief factors, and lastly by examining antecedents and moderators of PU and PEOU (GayanNayanajith \& Damunupola, 2019; GayanNayanajith \& Dissanayake; 2019). Similarly, TAM had been successful in explaining many kinds of systems such as e-learning, learning management systems, web-based systems etc. Based on this discussion and review of literature following conceptual model was formulated for the study. 


\section{Conceptual model}

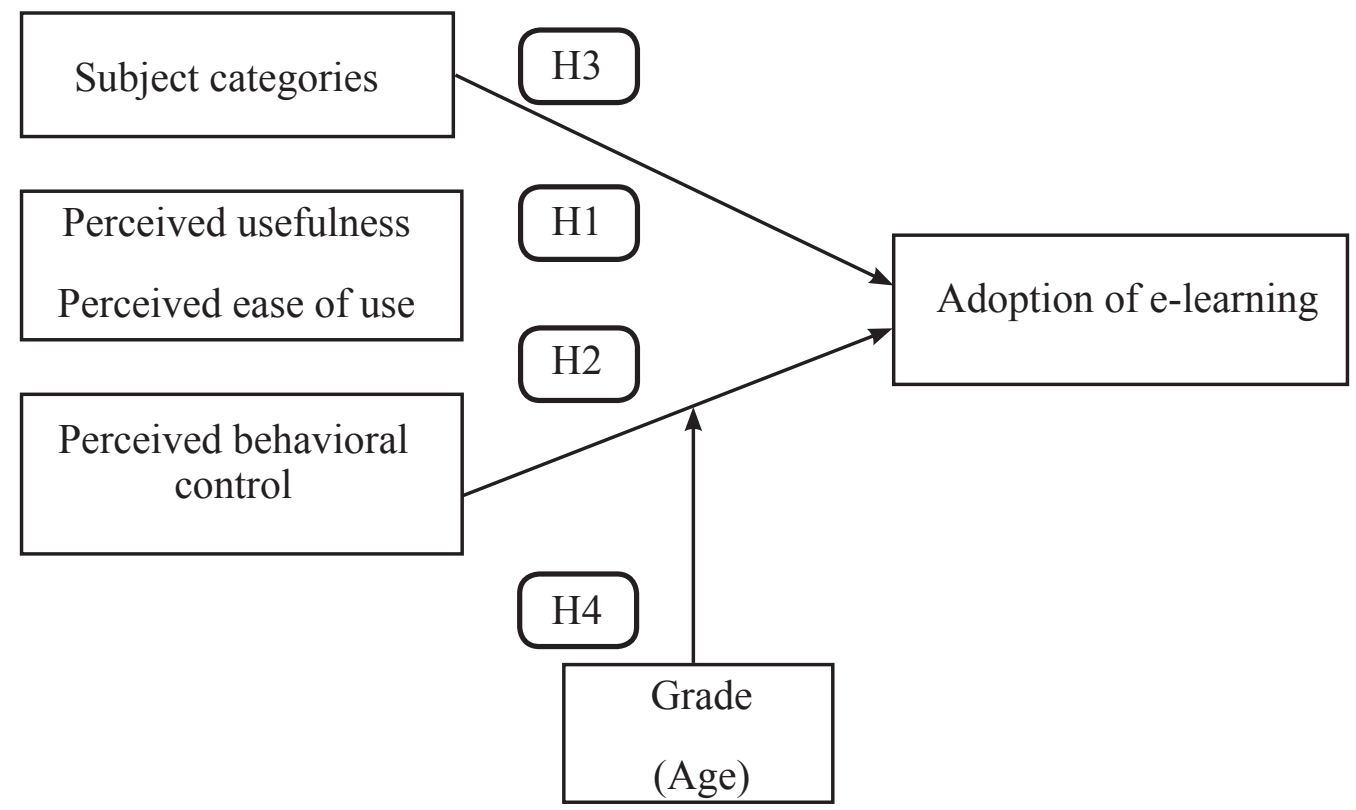

Figure 1: Conceptual model

PU is the one's perception of degree of enhancement of a particular task by a system and PEOU is the effort freeness of a system (Davis, 1989). PEOU was a predictor of PU; both the PU and the attitude of the user were predictors of intention to use (Liu, Liao \& Pratt, 2009).TAM variables are significantly predicting the AEL (Masrom, 2007).Determinants of the technology acceptance model are the major factors influencing the adoption of the technology(Cheung \& Vogel, 2013).Considering the aforesaid facts, following hypothesis is proposed,

$\mathrm{H}_{1} 1$-There is a positive relationship with PU and PEOU on AEL

It was revealed that "intention" and "user satisfaction" both had positive effects on actual use of e-learning (Mohammadi, 2015). Self-efficacy, SN are most influencing and then PU, PEOU affects AEL (Park, 2009). A successful e-learning system should integrate the components of both utility and fun (Zhang et al., 2008).Students'e $\square$ satisfaction has a direct relationship with students' e $\square$ retention(Al-Hawari \& Mouakket, 2010).Considering the aforementioned facts, following hypothesis is proposed,

$\mathrm{H}_{1}$ 2-There is a positive relationship with $\mathrm{PBC}$ and AEL

The integration of perceived satisfaction and technology acceptance in accordance with psychological traits and learner beliefs have been highlighted by several researchers (Al-Azawei, Parslow\& Lundqvist, 2017).Considering the aforementioned facts, following hypothesis is proposed, 
$\mathrm{H}_{1} 3$-There is a difference in AEL between the students enrolled for aesthetic subject category and other subject category students (commerce\& science students)

Subjective norm represented by peers is found to significantly moderate the relationship between attitude and intention toward the technology (Cheung \& Vogel, 2013).Results of the metaanalysis demonstrated a moderating effect for user-related factors and technology-related factors for several evaluated causal paths (ŠUmak, HeričKo \& PušNik, 2011).Social identity and social bonds could moderate the effect of subjective norms on intention (Chu \& Chen, 2016). Among the individual differences namely, age, gender and experience; age moderates the behavioral intention and technology use (El-Masri \& Tarhini, 2017). Similarly, moderating effects of demographic characteristics such as age, gender, profession have been recognized in relation to other service sector industries such as banking with special reference to online banking adoption context as well by the researchers (Gayan Nayanajith et al., 2019). In view of the aforementioned facts, following hypothesis is proposed,

$\mathrm{H}_{1}$ 4-There is a moderation effect of grade of the student (age) on the relationship of PBC and AEL

\section{Methodology}

Deductive methodology and quantitative method had been used in the study. Saunders et al. (2012) specified that questionnaires can be utilized to examine and explicate relationships between variables. Due to the large sample and considering the expenditure, questionnaire survey deemed suitable. Respondents were the students of three leading private international schools operating in Sri Lanka. Initially, consent of the institutions was obtained through the e-mail correspondence. Privacy is a key principle that links to or underpins several other principles considered in research ethics. Respect for respondents and others, the avoidance of harm, the voluntary nature of participation, informed consent, ensuring confidentiality and maintaining anonymity, responsibility in the analysis of data and reporting of findings, and compliance in the management of data are all linked to or motivated by the principle of ensuring the privacy of those taking part and associated to the research study are all complied. Respondents were selected on multi-level cluster sampling method as per provinces/districts and major cities in which these schools are in operation. Class teachers, those who are in charge of the classes were selected as enumerators for data collection process of this research. Enumerators have collected data through self-administered questionnaires from the individual students who have attended to the completion of the questionnaire during week-ends at their residences and returned subsequently. Altogether 450 questionnaires were distributed and 271 duly completed questionnaires (60\%) were considered for the final data analysis.

For most of the academic research studies involving individuals or institutions' representatives, questionnaire response rates of approximately 50 per cent and 35 to 40 per cent correspondingly are reasonable (Baruch \&Holtom 2008). Response rates that are in between 10 and 50 per cent for postal questionnaire surveys and up to 90 per cent for face-to-face interviews have also been suggested (Neuman, 2005; Saunders et al., 2012). With reference to telephone questionnaires, response rates have fallen from 70 to 80 per cent to less than 40 per cent, as a result of usage of answering services by the public to screen calls (Dillman, 2009). Hence, it could be noted that the response rate of the study is in line with the previous researchers' experiences and this will not be having any adverse effect on proceeding the study. 
PBC is a latent variable and there are several constructs that determine the PBC such as attitudes, $\mathrm{SN}$, self-efficacy, facilitating conditions etc. Hence, principal component analysis has been deployed enabling identification of factors related to PBC. Subsequently, reliability analysis was performed using Cronbach's alpha coefficients on PBC, adoption and on the dependent variable; AEL. To determine the relationship Pearson's correlation coefficient used. Regression analysis performed to investigate the coefficients and degree of explanation of AEL by the model. Anova with planned contrasts used to determine the differences in AEL in different subject categories. Trend variables were determined by the Anova trend analysis. Covariate effect on adoption is investigated by Ancova. Similarly, Hayes' process was used to analyze the moderating effect of grade of the student (student's age) in between PBC and AEL.

Accordingly, IBM SPSS 20 with Hayes's process version 3.4 was used for analysis. Initial analysis demonstrated that most of the demographic characteristics of the population are being replicated vastly by the elected sample.

\section{Results}

Since AEL is a latent variable that could not be directly observed, principle component analysis (PCA) was conducted on the 24 items of PBC (Table 1) with orthogonal rotation (varimax). The Kaiser-Meyer-Olkin (KMO) measure verified the sampling adequacy for the analysis, KMO = .89 which is quite sufficient and all $\mathrm{KMO}$ values for individual items were $>.7$, which is well above the acceptable limit of .5 (Field, 2013). Bartlett's test of sphericity $\chi^{2}, p<.001$, indicated that correlations between items were sufficiently large for PCA.

Table 1. Summary of PCA results of PBC items $(N=271)$

\begin{tabular}{lllll}
\hline \multicolumn{5}{c}{ Rotated factor loading } \\
\hline Attitudes & SN & Self-efficacy & $\begin{array}{l}\text { Facilitating } \\
\text { condi. }\end{array}$ \\
\hline No. of items & 8 & 8 & 4 & 4 \\
Eigen values & 7.32 & 1.91 & 1.32 & 1.24 \\
Percentage of variance & 31.40 & 7.91 & 5.82 & 5.77 \\
\hline
\end{tabular}

Source: Survey data 2019

Cronbach's alpha values (Table 2) are higher than 0.7. Moreover, K-S test and Levene's test performed to ensure normal distribution of respondents' data and homoscedasticity where results were not significant for both the tests.

Table 2. Reliability analysis

\begin{tabular}{lllll}
\hline & No. of items & Cronbach's alpha & Mean & $\begin{array}{l}\text { Standard } \\
\text { deviation }\end{array}$ \\
\hline Adoption & 10 & .962 & 4.38 & .55 \\
PBC & 24 & .988 & 3.78 & .63 \\
AEL & 6 & .884 & 4.45 & .44 \\
& & & & \\
\hline
\end{tabular}

Source: Survey data 2019 
Pearson correlation analysis revealed that the AEL possesses a positive relationship with both PBC and adoption variables whilst both the relationships were significant at .01 level (1-tailed).

Table 3. Correlation matrix

\begin{tabular}{llll}
\hline & AEL & PBC & Adoption \\
\hline AEL & 1 & & \\
PBC & $.875^{* *}$ & 1 & 1 \\
Adoption & $.916^{* *}$ & $.847^{* *}$ &
\end{tabular}

** Correlation is significant at the 0.01 level (1-tailed)

Source: Survey data 2019

A multiple regression analysis was conducted using hierarchical method to predict the degree to which independent variables; adoption and PBC impact the AEL(Table 4). In accordance with model 1, the overall variance of AEL explained by $\mathrm{PBC}$ is $76.2 \%$ as per the adjusted $\mathrm{R}$ square figure. According to the significance value, model 1 is statistically significant.

Table 4. Regression output (Model 1 \& 2)

\begin{tabular}{llclllll}
\hline & $t$ & Sig. & $\square$ & F Change & $d f$ & Sig. $F$ & Adj. $R^{2}$ \\
& & & & & & Change & \\
\hline Model 1 & & & & 881.14 & 1 & .000 & .765 \\
(Constant) & 26.29 & .000 & 2.108 & & & & \\
PBC & 29.68 & .000 & 0.621 & & & & \\
\hline
\end{tabular}

Dependent variable: AEL

Source: Survey data 2019

In accordance with model 2, the overall variance of AEL explained by PBC and adoption is $87.4 \%$ as per the adjusted $\mathrm{R}$ square figure. According to the significance value, model 2 is also statistically significant.

For the current model the VIF and Tolerance values recorded as 3.535 and .283 which are well below 10 and above 0.2 subsequently; therefore, no collinearity within the data (Field, 2013). Even the average VIF which is also 3.535 is not substantially greater than 1 which also shows that there is no cause for concern.

To determine the cases which are influencing the regression model, case-wise diagnostics, Cook's distance, Mahalanobis distance, DFBeta statistics and covariance ratio (CVR) were checked and all were in order. In order to generalize the model beyond the sample, it is necessary to check some of the assumptions of regression residuals. Graph of standardized residuals (ZRESID) 
and dependent variable (ZPRED) checked, histograms looked like normally distributed and P-P plot looked like curving around a diagonal line which is supportive for generalizing the model beyond the sample. Therefore, it could be summarized that the model appears in most senses to be both accurate for the sample and generalizable to the population of interest as the assumptions have been met and could be safely assumed that this model would generalize to AEL in Sri Lankan context.

In order to examine the specific hypothesis stated as, there are differences between lower income group and higher income groups, one-way ANOVA with planned contrasts was performed (Table $5 \&$ Table 6). There was a significant effect of income on AEL, $F(2,268)=244.01, p<.05, \omega=$ .80 . Secondly, there was a significant linear trend, $F(1,268)=459.97, p<.01, \omega=.78$, indicating that as the income increases AEL also increases proportionately.

Table 5. One-way ANOVA-Trend analysis results

\begin{tabular}{lllllll}
\hline & & Sum of & df & Mean & $F$ & Sig. \\
& & Square & & Square & & \\
\hline \multicolumn{2}{c}{ Between Groups (Combined) } & 34.479 & 2 & 17.239 & 244.007 & .000 \\
\multicolumn{1}{c}{ Linear Term } & Unweighted & 32.497 & 1 & 32.497 & 459.972 & .000 \\
& Weighted & 33.796 & 1 & 33.796 & 478.353 & .000 \\
& Deviation & .683 & 1 & .683 & 9.661 & .002 \\
\multicolumn{1}{c}{ Quadratic Term } & Unweighted & .683 & 1 & .683 & 9.661 & .002 \\
& Weighted & .683 & 1 & .683 & 9.661 & .002 \\
Tithin Groups & & 18.934 & 268 & .071 & & \\
\hline
\end{tabular}

Source: Survey data 2019

Table 6. One-way ANOVA-Contrast test results

\begin{tabular}{|c|c|c|c|c|c|c|}
\hline Contrast & & $\begin{array}{l}\text { Value of } \\
\text { Contrast }\end{array}$ & Std. Error & $t$ & $\mathrm{df}$ & Sig. \\
\hline Assume equal variances & 1 & 1.8647 & .08555 & 21.796 & 268 & .000 \\
\hline & 2 & .4810 & .04567 & 10.531 & 268 & .000 \\
\hline Does not assume equal & 1 & 1.8647 & .08314 & 22.429 & 60.925 & .000 \\
\hline variances & 2 & .4810 & 02169 & 22.174 & 174.000 & .000 \\
\hline
\end{tabular}

Source: Survey data 2019

Main findings of ANCOVA as depicted in table 7, revealed that the covariate, participant's age was not significantly related to the participant's AEL, $F(1,267)=1.776, p>.05$, partial eta 
Impact of Perceived Behavioral Control on E-learning Adoption ... / 9

squared $=.007$. However, there was a significant effect of income levels on AEL after controlling for the effect of participant's age, $F(2,267)=147.947, p<.05$, partial eta squared $=.526$.

Table 7. ANCOVA-Tests of between-subjects effects

Dependent Variable: AEL

\begin{tabular}{lllllll}
\hline Source & $\begin{array}{l}\text { Type III Sum } \\
\text { of Squares }\end{array}$ & Df & $\begin{array}{l}\text { Mean } \\
\text { Square }\end{array}$ & $F$ & Sig. & $\begin{array}{l}\text { Partial Eta } \\
\text { Squared }\end{array}$ \\
\hline Corrected & $34.604^{\mathrm{a}}$ & 3 & 11.535 & 163.734 & .000 & .648 \\
Model & & 1 & 277.211 & 3935.025 & .000 & .936 \\
Intercept & 277.211 & 1 & .125 & 1.776 & .184 & .007 \\
Age & .125 & 2 & 10.422 & 147.947 & .000 & .526 \\
Income & 20.845 & 267 & .070 & & & \\
Error & 18.809 & 271 & & & & \\
Total & 5433.694 & 270 & & & & \\
Corrected & 53.413 & 270 & & & \\
Total & & & & & & \\
\hline
\end{tabular}

a. $\mathrm{R}$ Squared $=.648($ Adjusted $\mathrm{R}$ Squared $=.644)$

Source: Survey data 2019

Output of the moderation analysis (Table 8) has shown a moderation effect attributable to the significant interaction of PBC and age and in this study the interaction is highly significant, $b=$ $-.23,95 \%$ confidence interval (CI) $(-.32,-.14), t=-5.09, p<.01$, indicating that the relationship between $\mathrm{PBC}$ and AEL is moderated by age.

Table 8- Moderation analysis output- as per Hayes's process version 3.4 for SPSS

\begin{tabular}{lllll}
\hline & $b$ & $S E B$ & $t$ & $p$ \\
\hline Constant & .53 & .32 & 1.66 & .0991 \\
PBC & 1.05 & .09 & 11.58 & .0000 \\
Age & .88 & .17 & 5.21 & .0000 \\
PBC x Age & -.23 & .05 & -5.09 & .0000 \\
\hline
\end{tabular}

Source: Survey data 2019

\section{Discussion}

Consistent with the empirical results given in preceding section, AEL has been significantly predicted by adoption dimensions and PBC factors in the context of private school chains in Sri Lanka, while supporting hypothesis one and two.

Results of a study using an integrated model in Jordan has indicated that perceived ease of use, perceived usefulness, system quality, information quality, and computer self-efficacy are major factors influencing students' satisfaction and adoption of e-learning (Hammouri \& AbuShanab, 2018). Another study examining on the successful integration of e $\square$ learning systems 
in higher education in Iraq, from the perspective of the students has noted that perceived ease of use and perceived usefulness are significantly affect adoption of e-learning systems (Ameen et al., 2019). Similarly, several researchers have noted that even in different country contexts including Sri Lanka, perceived ease of use, perceived usefulness are among key variables that are affecting adoption of computer aided learning, adoption of tourism related technologies and user acceptance of internet banking services, to a greater extent (Cheung \& Vogel, 2013; Nayanajith, 2020; Nayanajith \& Damunupola, 2019a; Nayanajith et al., 2019b; Zhang et al., 2008).

Further, results of correlation analysis outcome noted that two aforementioned independent variables (PU \& PEOU) were positively correlated with AEL. Additionally, there are empirical evidences supporting the positive relationship between adoption and PBC variables on AEL (Chu et al., 2016). Therefore, the findings of present research study conform to the previous findings. Furthermore, main constructs of adoption are the perceived ease of use (PEOU) and the perceived usefulness (PU). Thus, this research is consistent with the findings related to TAM. According to the regression analysis using hierarchical method, although adoption and PBC constructs are governing variables as per the study, there are other factors which were not discussed in this study that impacts the AEL. In addition, planned contrasts revealed by supporting third hypothesis, that engaging in science subjects significantly increases AEL compared to engaging in aesthetic subjects and that engaging in science subjects significantly improved AEL compared engaging in commerce subjects.

Several researchers have noted that adoption of e-learning based on science, mathematics, engineering and technology subjects are high with regard to developing students' higher order thinking skills (Yusuf et al., 2018). Further, technology acceptance in line with psychological traits and learner beliefs have been highlighted by several researchers (Al-Azawei, et al., 2017; Nayanajith et al., 2019c). Similarly, another research study supported the instructional suggestions towards science learning in digital environments based on a review of eye tracking studies (Yang et al., 2018).In the meantime, researchers have identified the moderating effects of socio-demographic characteristics of the users towards adoption of technology in service sector industries including financial services alongside other technology adoption antecedents such as website usability, e-service quality and technology self-efficacy (Chu \& Chen, 2016; Nayanajith et al., 2020b; Nayanajith et al., 20219d\&2019e; ŠUmak, et al., 2011).Moreover, study revealed that the covariate, age was not significantly related to the participant's AEL in the research context while the moderation analysis has confirmed relationship between PBC and AEL is being moderated by the age of the student which is in line with empirical evidences; whilst supporting the fourth hypothesis(El-Masri \& Tarhini,2017; Nayanajith \& Damunupola, 2019b).

This research study delivers important implications for practitioners, policy makers and students as well as other stakeholders such as e-learning application developers $n$ etc. E-learning facilities that is being perceived as yielding low achievement is unlikely to be linked to an intention to adopt the e-learning. Connecting this to previous literature that indicates prior experience of lowvalue e-learning is likely to yield poor student or user perception of e-learning, since students may not always separate e-learning into content, pedagogy and the complex network of hard and soft technology, practitioners and e-learning service developers should ensure that the content, 
design, pedagogy, implementation and technology are all perceived as high value to learners if a course is to be adopted via online learning platforms provisioning ease of use and make it useful for the users.

Practitioners implementing e-learning facilities in college contexts should also be aware of the link between perceived cost and usefulness in achievement whilst providing greater ease of use. Practical considerations for teachers and administrators may include providing sufficient time and resources to complete e-learning courses and delivering appropriate reward following e-learning, for instance, a certificate confirming the achievement and follow-up courses for further development enabling to strengthen perceptions towards higher behavioral control.

School administrators could make use of e-learning adoption strategies in view of engaging more students towards following particularly science, mathematics, engineering and technology subject areas whilst focusing on socio demographic characteristics of users. In summary, this study reiterates the importance of students' perceptions on ease of use and usefulness as well as their perception on the ability to perform e-learning facilities towards adoption of e-learning particularly in Sri Lankan private international schools' context enabling stakeholders to prioritize the discussed antecedents for successful implementation of e-learning across Sri Lanka.

\section{Conclusion and Recommendations}

Data analysis supported all hypotheses; positive relationship of $\mathrm{PBC}$ and adoption construct on AEL, existence of differences in AEL, between students of different subject streams and moderation effect of age between PBC and AEL. In practical scenario, all these international school chains perform relatively well in the presence of sporadic technology changes. Yet, the schools cannot undermine the threat of foreign education facilitators which are invading the local sphere to a greater extent with latest technology-based distance learning education services, amidst challenging supervisory and regulatory developments. Therefore, it is recommended marketers of local education service providers, to capitalize awareness on PEOU and PU dimensions in conjunction with PBC, innovativeness, developing trustworthiness, information security of web-based learning modules and etc. Research findings are beneficial for the education service providers and policy makers, particularly the schools, universities and tuition service providers, enabling them to execute segmenting, targeting and profiling their students with the assistance of previously discussed factors alongside differentiation on demographic/personal characteristics related to individual students.

Current study is also subjected to several limitations with time and resource constraints. Nevertheless, future researches could be performed with greater representation of the entire population to validate the research findings in search of diverse findings in different country, cultural and societal contexts. Similarly, diverse research approaches and perspectives alongside the usage of novel and different models on technology adoption related to online learning, cloudbased learning, computer aided collaborative learning etc. will undoubtedly uplift the significance of future researches. 


\section{References}

Ajzen, I. (1991). The theory of planned behavior. Organizational Behavior and Human Decision Processes, 50(2), 179-211.

Ajzen, I. (2002). Perceived behavioral control, self $\square$ efficacy, locus of control, and the theory of planned behavior. Journal of Applied Social Psychology, 32(4), 665-683.

Al-Azawei, A., Parslow, P., \& Lundqvist, K. (2017). Investigating the effect of learning styles in a blended e-learning system: An extension of the technology acceptance model (TAM). Australasian Journal of Educational Technology, 33(2).

Al-Hawari, M. A., \&Mouakket, S. (2010). The influence of technology acceptance model (tam) factors on students'e-satisfaction and e-retention within the context of uae e-learning. Education, Business and Society: Contemporary Middle Eastern Issues, 3(4), 299314.

Ameen, N., Willis, R., Abdullah, M. N., \& Shah, M. (2019). Towards the successful integration of e $\square$ learning systems in higher education in Iraq: A student perspective. British Journal of Educational Technology, 50(3), 1434-1446.

Andy, F. (2009). Discovering statistics using SPSS. London: UK.

Bagozzi, R. P., Davis, F. D., \&Warshaw, P. R. (1992). Development and test of a theory of technological learning and usage. Human relations, 45(7), 659-686.

Baruch, Y., \&Holtom, B. C. (2008). Survey response rate levels and trends in organizational research. Human relations, 61(8), 1139-1160.

Central Bank of Sri Lanka 2018 Annual Report 2018, Sri Lanka: Central Bank of Sri Lanka.

Cheung, R., \& Vogel, D. (2013). Predicting user acceptance of collaborative technologies: An extension of the technology acceptance model for e-learning. Computers \& Education, $63,160-175$.

Chu, T. H., \& Chen, Y. Y. (2016). With good we become good: Understanding e-learning adoption by theory of planned behavior and group influences. Computers \& Education, 92, 3752 .

Davis, F. D. (1989). Perceived usefulness, perceived ease of use, and user acceptance of information technology. MIS quarterly, 319-340.

Davis, F. D., Bagozzi, R. P., \& Warshaw, P. R. (1989). User acceptance of computer technology: a comparison of two theoretical models. Management science, 35(8), 982-1003.

Dillman, D. A., Phelps, G., Tortora, R., Swift, K., Kohrell, J., Berck, J., \& Messer, B. L. (2009). Response rate and measurement differences in mixed-mode surveys using mail, telephone, interactive voice response (IVR) and the Internet. Social Science Research, 38(1), 1-18.

El-Masri, M., \&Tarhini, A. (2017). Erratum to: Factors affecting the adoption of e-learning systems in Qatar and USA: Extending the Unified Theory of Acceptance and Use of 
Impact of Perceived Behavioral Control on E-learning Adoption ... / 13

Technology 2 (UTAUT2). Educational Technology Research and Development, 65(3), 765-767.

GayanNayanajith, D. A. \& Dissanayake, D. M. R. (2019) "E-Banking Adoption in the Context of Innovation and E-Service Quality: A Review on Concepts and Practices", Journal of Environmental Science, Computer Science and Engineering \& Technology, 8(3), 208221, https://doi.org/10.1108/02652320310457776

GayanNayanajith, D. A. \&Damunupola, K. A. (2019) "E-Service Trustworthiness and Adoption of Online Banking in the Presence of a Moderator: A Relational Study", Journal of Environmental Science, Computer Science and Engineering \& Technology, 8(4), 265289, DOI: $10.24214 /$ jecet.B.8.4.26589.

GayanNayanajith, D. A., Weerasiri, R. A. S. \& Damunupola, K.A. (2019) "A Review on E-Banking Adoption in the Context of E-Service Quality", Sri Lanka Journal of Marketing, 5(2), 25-52.

Hammouri, Q., \& Abu-Shanab, E. (2018). Exploring factors affecting users' satisfaction toward E-learning systems. International Journal of Information and Communication Technology Education (IJICTE), 14(1), 44-57.

Jalali, S. M. J., Mahdizadeh, E., Mahmoudi, M. R., \& Moro, S. (2018). Analytical assessment process of e-learning domain research between 1980 and 2014. International Journal of Management in Education, 12(1), 43-56.

Liu, S. H., Liao, H. L., \& Pratt, J. A. (2009). Impact of media richness and flow on e-learning technology acceptance. Computers \& Education, 52(3), 599-607.

Masrom, M. (2007). Technology acceptance model and e-learning. Technology, 21(24), 81.

Mohammadi, H. (2015). Investigating users' perspectives on e-learning: An integration of TAM and IS success model. Computers in Human Behavior, 45, 359-374.

Nayanajith, D. A. G., (2020). Multivariate Analysis of User Intentions and Actions Towards Acceptance of Tourism Related Technology, Journal of Management and Tourism Research, 3(1), 13-26.

Nayanajith, G., \&Damunupola, K. A. (2019a). Effects of Subjective Norms and Security on Online Banking Adoption: Multilevel Linear Model Analysis. Asian Journal of Multidisciplinary Studies, 2(1).

Nayanajith, G., \&Damunupola, K. A. (2019b). Relationship of Perceived Behavioral Control and Adoption of Internet Banking in the Presence of a Moderator. Asian Journal of Multidisciplinary Studies, 2(2).

Nayanajith, G., Damunupola, K. A., \& Pastor, C. K. (2020). Telebanking Adoption Intentions, Actions and Subjective Norms in the Context of Sri Lankan Private Commercial Banks. Southeast Asian Journal of Science and Technology, 5(1).

Nayanajith, G., Damunupola, K. A., \& Pastor, C. K. L. (2020). E-Service Quality, Technology Self-Efficacy and Smart Banking Adoption in Sri Lanka. ASEAN Multidisciplinary Research Journal, 4(1), 25-32. 
Nayanajith, G., Damunupola, K. A., \& Ventayen, R. J. (2019a). User Intentions and Actions Towards Adoption of Technology Based Self-Service Banking Services: A MANOVA Analysis. Southeast Asian Journal of Science and Technology, 4(1).

Nayanajith, G., Damunupola, K. A., \&Ventayen, R. J. (2019b). Relationship of Perceived Trust and Perceived Ease of Use on Adoption of Computer Aided Learning in the Context of Sri Lankan International Schools. Southeast Asian Journal of Science and Technology, 4(1).

Nayanajith, G., Damunupola, K. A., \&Ventayen, R. J. (2019c). Impact of Innovation and Perceived Ease of Use on E-Learning Adoption. Asian Journal of Business and Technology, 2(1).

Nayanajith, G., Damunupola, K. A., \&Ventayen, R. J. (2019d). Website Usability, Perceived Usefulness and Adoption of Internet Banking Services in the Context of Sri Lankan Financial Sector. Asian Journal of Business and Technology, 2 (1).

Nayanajith, G., Damunupola, K. A., \&Ventayen, R. J. M. (2019e). Online Banking Transactions and Mere-Exposure Effect. Online Journal of Technology Innovation, 2.

Neuman, W. L. (2005). Social Research Methods. (6. Basim).

Park, S. Y. (2009). An analysis of the technology acceptance model in understanding university students' behavioral intention to use e-learning. Educational Technology \& Society, 12(3), 150-162.

Saunders, M. N. (2011). Research Methods for Business Students, 5/e. Pearson Education India.

ŠUmak, B., HeričKo, M., \& PušNik, M. (2011). A meta-analysis of e-learning technology acceptance: The role of user types and e-learning technology types. Computers in Human Behavior, 27(6), 2067-2077

Yang, F. Y., Tsai, M. J., Chiou, G. L., Lee, S. W. Y., Chang, C. C., \& Chen, L. L. (2018). Instructional suggestions supporting science learning in digital environments based on a review of eye tracking studies. Journal of Educational Technology \& Society, 21(2), $28-45$.

Yusuf, I., Widyaningsih, S. W., \& Sebayang, S. R. B. (2018). Implementation of E-learning based-STEM on Quantum Physics Subject to Student HOTS Ability. Journal of Turkish Science Education, 15(Special), 67-75.

Zhang, S., Zhao, J., \& Tan, W. (2008). Extending TAM for online learning systems: An intrinsic motivation perspective. Tsinghua Science and Technology, 13(3), 312-317. 